\title{
Inula graveolens induces selective cytotoxicity in glioblastoma and chronic leukemia cells
}

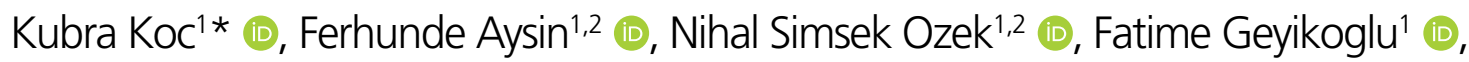

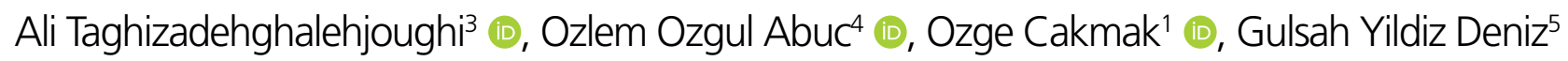

\section{SUMMARY}

OBJECTIVE: Crude oil extracts, components of extracts, and ethanolic extracts of Inula graveolens possess various pharmacological activities on various cancer cells including antioxidative and antiproliferative effects. Aqueous extract of this species has not been investigated on the liquid malignancies and solid tumors with a high incidence of treatment refractoriness and poor survival outcomes such as glioblastoma and leukemia. Hence, the present study aimed to evaluate the cytotoxic efficiency of $I$. graveolens aqueous extracts on human glioblastoma multiforme and chronic myelogenous leukemia cell lines in comparison to non-cancerous primary rat cerebral cortex and human peripheral blood mononuclear cells.

METHODS: The cells were treated with the extracts of $I$. graveolens $(125-1000 \mu \mathrm{g} / \mathrm{mL}$ ) for $48 \mathrm{~h}$, the cellular viability was identified using 3'-(4,5dimethylthiazol-2-yl)-2,5-diphenyl tetrazolium bromide assay, and lactate dehydrogenase release was measured to determine the cytotoxic potential. Total oxidant status and apurinic/apyrimidinic endodeoxyribonuclease 1 assays were used to determine the oxidative status of cells and DNA damage, respectively.

RESULTS: I. graveolens showed selective cytotoxicity toward human glioblastoma multiforme and chronic myelogenous leukemia cell lines and exhibited a higher antiproliferative effect against cancer cells in comparison to non-cancerous cells. Moreover, it significantly reduced the apurinic/apyrimidinic endodeoxyribonuclease 1 levels on both cancer cell lines as compared with their control cells without changing the levels of an oxidative stress marker.

CONCLUSION: The extracts of $I$. graveolens have anti-cancer potential on human glioblastoma multiforme and chronic myelogenous leukemia cell lines without causing oxidative stress.

KEYWORDS: Glioblastoma. Myeloid leukemia. Inula. Cell viability.

\section{INTRODUCTION}

Inula graveolens (Dittrichia graveolens) is an annual plant that is sticky, strongly aromatic, and widely distributed in the Mediterranean area ${ }^{1}$. The essential oil and extracts of I. graveolens possess significant antioxidant, antiproliferative, and antibacterial activities, which have been demonstrated by pharmacological studies ${ }^{2-4}$. Previous phytochemical investigations of this plant have revealed the presence of oxygenated monoterpenes with high contents of bornyl acetate, borneol, and $\tau$-cadinol ${ }^{5}$. Besides, chlorogenic acid, quinic acid, hyperoside, protocatechuic acid, and quercetin are the major phenolic compounds of $I$. graveolens. The significant antioxidant capacity of $I$. graveolens has been thought to be related to the high

\footnotetext{
${ }^{1}$ Ataturk University, Faculty of Science, Department of Biology - Erzurum, Turkey.

${ }^{2}$ Ataturk University, East Anatolian High Technology Research and Application Center - Erzurum, Turkey.

${ }^{3}$ Ataturk University, Faculty of Veterinary Science, Department of Pharmacology and Toxicology - Erzurum, Turkey.

${ }^{4}$ Erzincan University, Faculty of Medicine, Department of Histology and Embryology - Erzincan, Turkey.

${ }^{5}$ Ataturk University, Vocational School of Health Services - Erzurum, Turkey.

*Corresponding author: kubrakc@hotmail.com

Conflicts of interest: the authors declare there are no conflicts of interest. Funding: This study was supported by the BAP from Atatürk University (FHD-2018-6722).

Received on September 03, 2021. Accepted on September 19, 2021.
} 
abundance of phenolic compounds $s^{6}$. Recently, the compounds isolated from I. graveolens have been recorded as an important antiradical power ${ }^{7}$. Moreover, the methanolic extract of I. graveolens has been shown that the antioxidant activity helps ameliorate the oxidative stress/antioxidant status balance in elite athletes during a competition period ${ }^{8}$. No recent reports are available about the antiproliferative potential aqueous extract of this species the liquid malignancies and solid tumors with a high incidence of treatment refractoriness and poor survival outcomes such as glioblastoma and leukemia. Therefore, the present study was conducted to clarify the anticancer potential of aqueous extract of I. graveolens on human glioblastoma multiforme (U-87 MG) and chronic myelogenous leukemia (K562) cancer cells concerning non-cancerous primary rat cerebral cortex (PRCC) and peripheral blood mononuclear cells (PBMCs).

\section{METHODS}

U-87 MG (ATCC ${ }^{\circledR}$ HTB-14) and K562 (ATCC ${ }^{\circledR}$ CCL-243) cell lines were obtained from American Type Culture Collection. The PRCC culture was obtained from the Department of Medical Pharmacology of Ataturk University, Erzurum, Turkey. The PBMCs were obtained from healthy volunteers. Whole blood was collected in the heparin blood tube and transferred to a conical tube containing $4 \mathrm{~mL}$ of phosphate-buffered saline (PBS). The diluted blood sample was carefully added onto a new conical tube containing $8 \mathrm{~mL}$ of Lymphoprep solution, and the blood was layered over the Lymphoprep solution. After centrifugation, the upper layer was aspirated carefully without disturbing the mononuclear cell layer containing lymphocytes, monocytes, and platelets at the interphase. The mononuclear cell layer was put into a new tube filled with PBS and centrifuged. The supernatant was discarded for the removal of platelets. The pellet was suspended in the RPMI medium supplemented with $10 \%$ fetal bovine serum (FBS) and $1 \%$ penicillin/streptomycin. The cells were disseminated into 24-well culture plates and cultured in 5\% $\mathrm{CO}_{2}$ and $95 \%$ moisture at $37^{\circ} \mathrm{C}$ for two days.

The aerial parts of $I$. graveolens were infused in distilled water at $98^{\circ} \mathrm{C}$ of temperature for $15 \mathrm{~min}$ and filtered. After sterilization, the infusion was diluted with a culture medium. Cell lines were grown in DMEM supplemented with $1 \%$ penicillin-streptomycin solution, $2 \mathrm{mM} \mathrm{L}$-glutamine, and $10 \%$ heat-inactivated FBS. Cells were grown to $80 \%$ confluency, and 10,000 cells/well were seeded into 96-well plates in triplicate. After $24 \mathrm{~h}$ of incubation, the medium was replaced with a fresh medium containing various concentrations $(125,250,500$, and $1000 \mu \mathrm{g} / \mathrm{mL})$ of $I$. graveolens according to our preliminary study.
After $48 \mathrm{~h}$ of treatments, the medium was removed and replaced with $150 \mu \mathrm{L}$ of 3'-(4,5dimethylthiazol-2-yl)-2,5-diphenyl tetrazolium bromide (MTT) stock solution (Sigma Chemical Company, St. Louis, USA). The plates were placed in an incubator at $37^{\circ} \mathrm{C}$ for $4 \mathrm{~h}$ and then MTT was replaced with $150 \mu \mathrm{L}$ of dimethyl sulfoxide. The absorbance was measured at $570 \mathrm{~nm}$ in a microplate reader. Lactate dehydrogenase (LDH) released from damaged cells was quantified by using a kit (Cayman Chemical Company, USA). The rate of NADH reduction directly proportional to $\mathrm{LDH}$ activity was measured as an increase in the absorbance at $490 \mathrm{~nm}$.

The total oxidant status (TOS) of cultured cells was measured using a commercial Rel Assay Diagnostics ${ }^{\circledR}$ Kit (Turkey). The amount of TOS in culture media was measured by the density of color change at $530 \mathrm{~nm}$.

Apurinic/apyrimidinic endodeoxyribonuclease 1 (APE1) level was examined from cell culture supernatants (ab207616, Abcam, UK). The absorbance (OD) was read at $450 \mathrm{~nm}$, and the concentration of the target in the samples was calculated by constructing a standard curve prepared from standard samples.

To compare the statistical significance of differences between the obtained results of the negative control and treated groups of I. graveolens aqueous part, statistical analysis was performed using a one-way analysis of variance (ANOVA) test followed by GraphPad Prism 6.0 statistics software (GraphPad, La Jolla, CA, USA). Tukey's test was used as a post hoc. Comparisons among the groups were represented as the mean \pm standard deviation (SD). A $p<0.05$ was considered statistically significant.

\section{RESULTS}

The cytotoxicity of the aqueous extracts of $I$. graveolens against human brain and leukemic cancer cells and non-cancerous cells was detected by MTT and LDH release assay. I. graveolens elicited a significant decrease in cell viability in both U-87 MG and K562 cell lines, which occurred in a dose-dependent manner. The extracts at the concentrations of 500 and $1000 \mu \mathrm{g} / \mathrm{mL}$ depicted considerable antiproliferative activity on U-87 MG cell lines $(\mathrm{p}<0.01$, reduction of $43 \%$ and $\mathrm{p}<0.001$, reduction of $50 \%$, respectively). However, more than $80 \%$ of PRCC remained viable after treatment with 500 and $1000 \mu \mathrm{g} / \mathrm{mL}$ of the extract $(\mathrm{p}<0.05)$, indicating that I. graveolens exhibited low cytotoxicity against PRCCs. Furthermore, the exposure to I. graveolens at the doses of 500 and $1000 \mu \mathrm{g} / \mathrm{mL}$ resulted in the $53 \%(\mathrm{p}<0.0001)$ and $73 \%(\mathrm{p}<0.0001)$ decrease in cell viability on $\mathrm{K} 562$ cells, but it is less toxic against healthy blood cells (Figure 1B). The same doses of the extract resulted in $33 \%(\mathrm{p}<0.0001)$ and $44 \%(\mathrm{p}<0.0001)$ decrease in cell viability on PBMCs. Treatment with $1000 \mu \mathrm{g} / \mathrm{mL}$ I. graveolens 


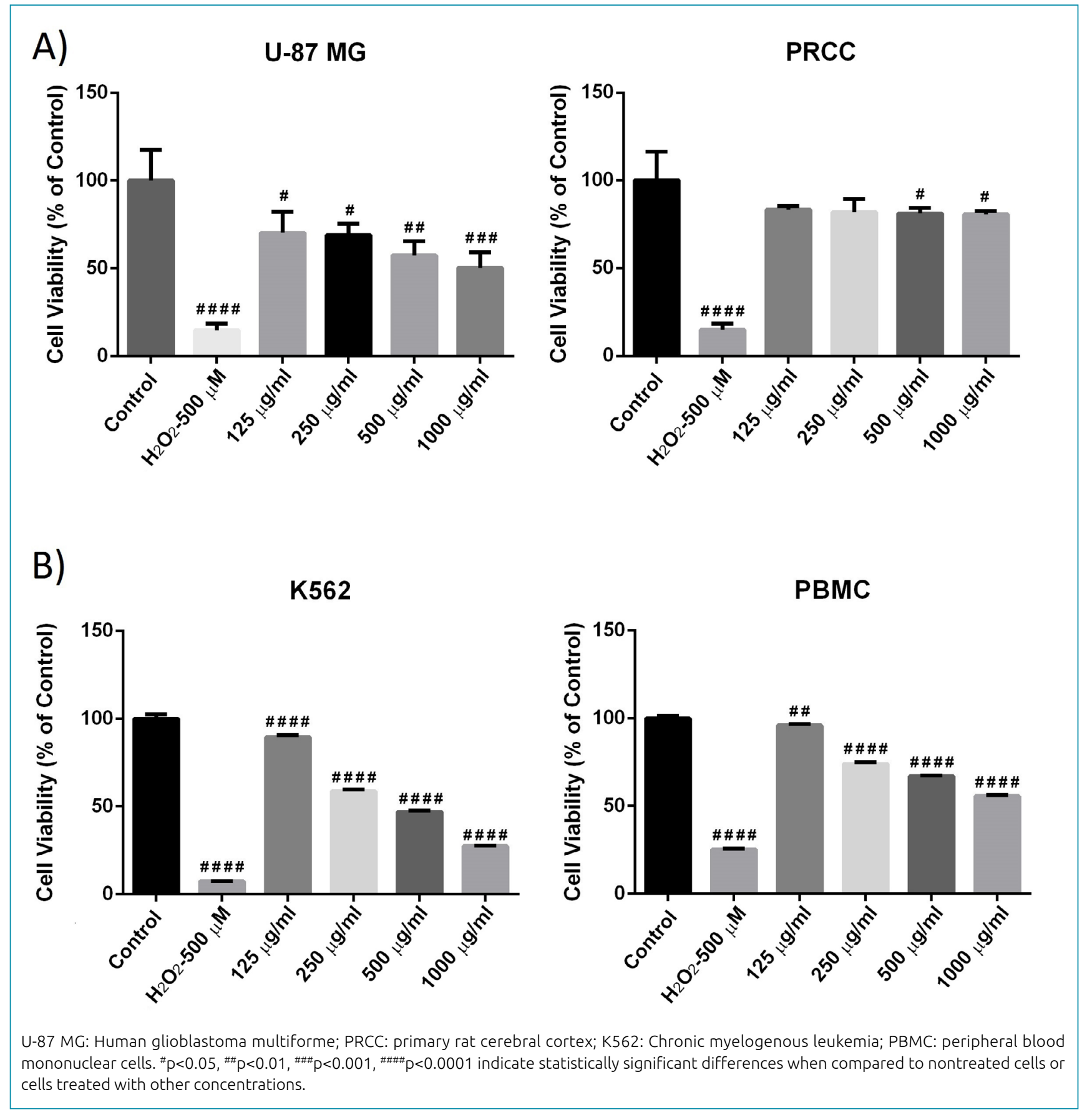

Figure 1. Cytotoxic effects of the I. graveolens extract against cell lines: (A) Human glioblastoma multiforme and primary rat cerebral cortex and (B) Chronic myelogenous leukemia and peripheral blood mononuclear cells after $48 \mathrm{~h}$ of incubation. The cellular viability was determined as the percentage of absorbance of $I$. graveolens treated cultures compared with those of untreated control cells, used as a negative control. Cells treated with $500 \mu \mathrm{m} \mathrm{H}_{2} \mathrm{O}_{2}$ were used as a positive control. Values are expressed as meantstandard deviation of three independent replicates.

resulted in more than 50\% viable PBMCs and PRCCs. Moreover, I. graveolens led to a remarkable increase in the LDH level of U-87 MG cells, while concentrations below $1000 \mu \mathrm{g} / \mathrm{mL}$ did not cause any change in PRCCs $(\mathrm{p}<0.001)$. The extract at 500 and $1000 \mu \mathrm{g} / \mathrm{mL} \mathrm{LDH}$ release significantly increased in $\mathrm{K} 562$ cells $(\mathrm{p}<0.001$ and $\mathrm{p}<0.0001$, respectively), while at the same concentrations, it did not cause any change in the LDH release of PBMCs (Figure 2). Thus, brain cancer and leukemic cells were more sensitive to I. graveolens than normal cells, implying that $I$. graveolens could damage the membrane 


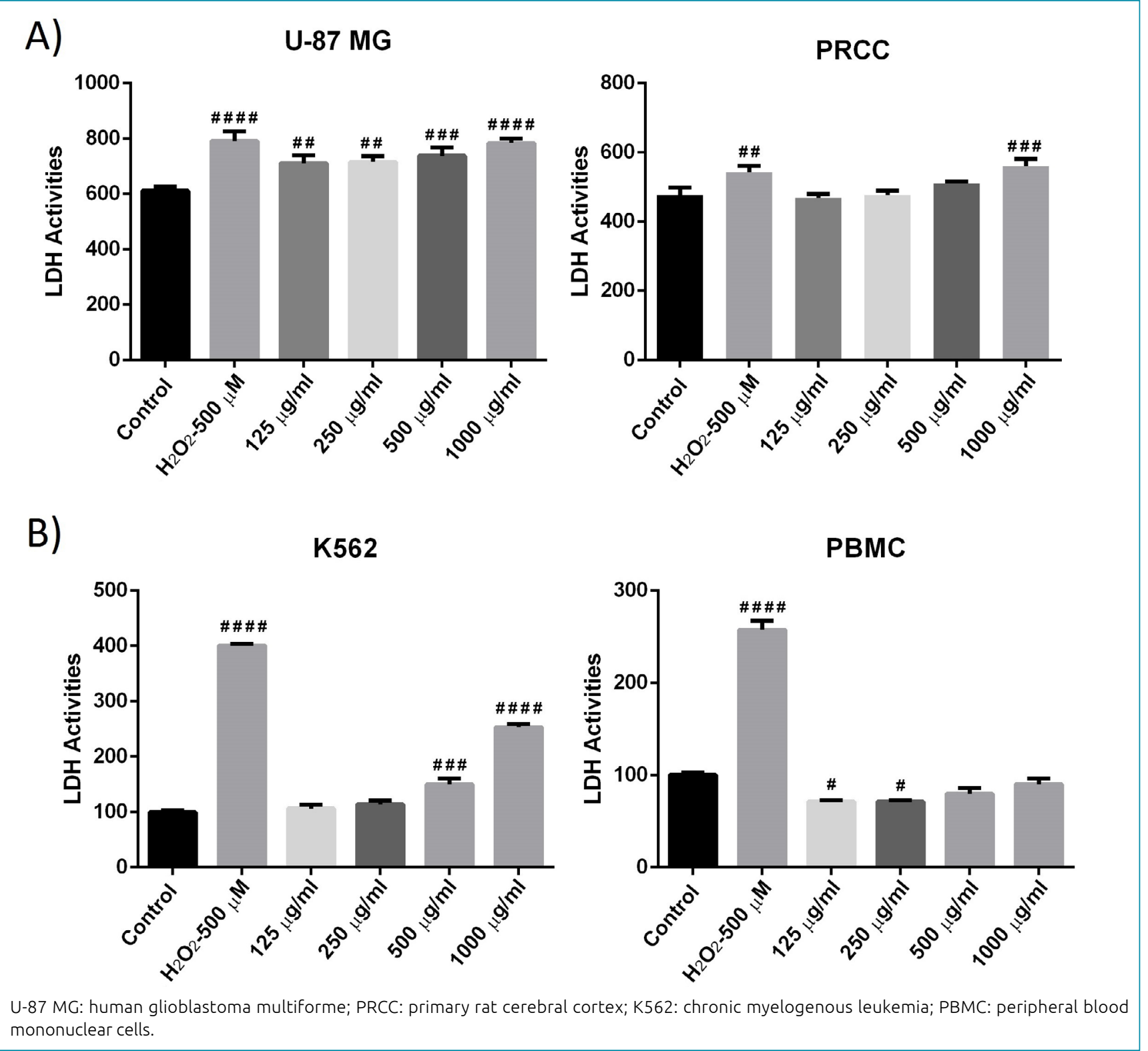

Figure 2. Effects of the I. graveolens extract on lactate dehydrogenase release in cell lines (A) Human glioblastoma multiforme and primary rat cerebral cortex and (B) Chronic myelogenous leukemia and peripheral blood mononuclear. Values are expressed

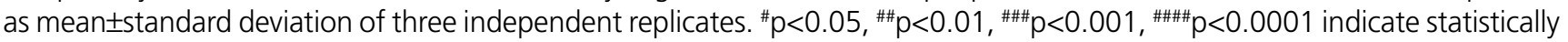
significant differences when compared to non-treated cells or cells treated with other concentrations.

integrity and resulting in dose-dependent induction of cellular toxicity.

Whether the extract from I. graveolens induced oxidative stress on the cells was tested by measuring the TOS level. The extracts at all concentrations did not cause any change in the TOS level of U-87 MG cells, while significantly reduced the TOS level of K562 cells. On the other hand, the extract at all concentrations tested did not cause any change in the TOS level on both non-cancerous cells (Figure 3).
APE1 activity was measured to investigate the DNA repair status of I. graveolens on cancer and non-cancerous cells. The level of APE1 significantly decreased in a dose-dependent manner on I. graveolens-treated U-87 MG cells compared with the control $(\mathrm{p}<0.05$ and $\mathrm{p}<0.01)$. Also, the level of APE1 decreased significantly at all concentrations of the extract on PRCC ( $\mathrm{p}<0.001)$. The level of APE1 in $\mathrm{H}_{2} \mathrm{O}_{2}$-treated $\mathrm{K} 562$ cells was also enhanced compared with the control $(\mathrm{p}<0.001)$. On the other hand, the level of APE1 decreased at all concentrations of the extract $(p<0.01)$. The extracts at concentrations above 
A)

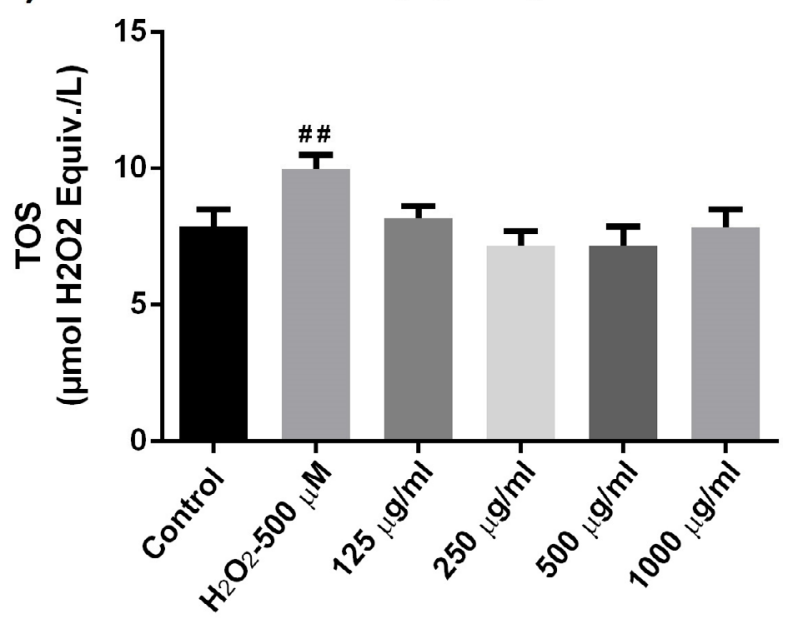

B)

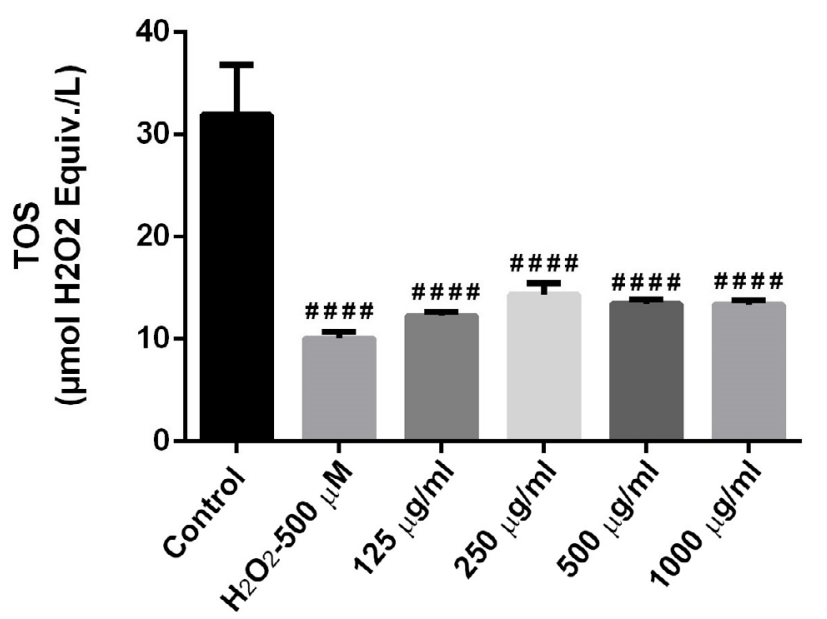

PRCC

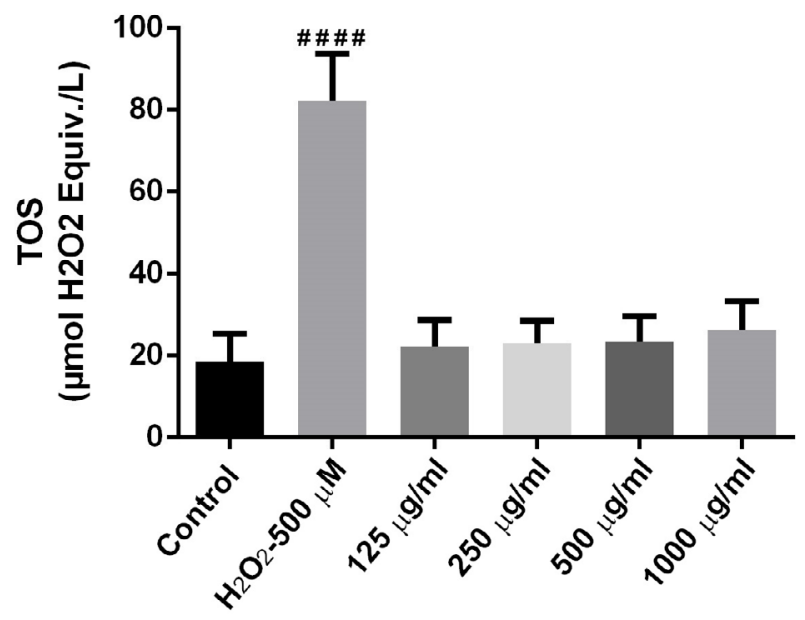

PBMC

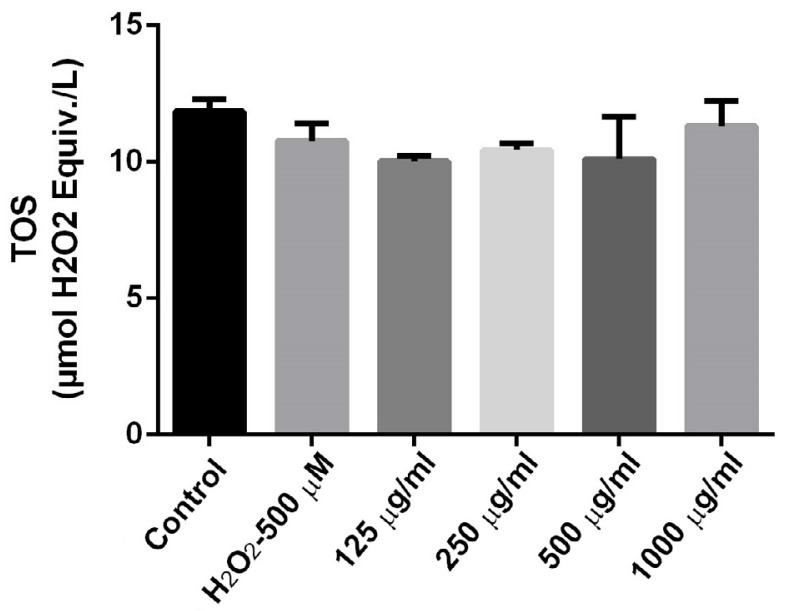

U-87 MG: Human glioblastoma multiforme; PRCC: primary rat cerebral cortex; K562: Chronic myelogenous leukemia; PBMC: peripheral blood mononuclear cells. "\#p<0.01, \#\#\# $p<0.0001$ indicate statistically significant differences when compared to nontreated cells or cells treated with other concentrations.

Figure 3. Effects of the I. graveolens extract on TOS level in cell lines: (A) human glioblastoma multiforme and primary rat cerebral cortex and (B) Chronic myelogenous leukemia and peripheral blood mononuclear. Values are expressed as mean \pm standard deviation of three independent replicates.

$125 \mu \mathrm{g} / \mathrm{mL}$ led to a dose-dependent increase at the APE1 level in PBMCs (Figure 4).

\section{DISCUSSION}

Many of the plants and their products provide numerous opportunities because of their unique properties including easy availability, easy biodegradability, easy handling, low cost, safety for mankind and the environment, greater acceptance among users, and minimum side effects ${ }^{9}$. Plant-derived compounds have been previously shown to suppress tumor onset, development, and progression and may diminish the disease and treatment-related side effects ${ }^{10}$. Similar biological and pharmacological activities of Inula species have been demonstrated in previous studies. The anticancer activities of I. graveolens were just reported only crude oil extracts, their components, and ethanolic extracts not aqueous parts ${ }^{4}$. Thus, this study aimed to evaluate the antiproliferative potential of aqueous extracts 


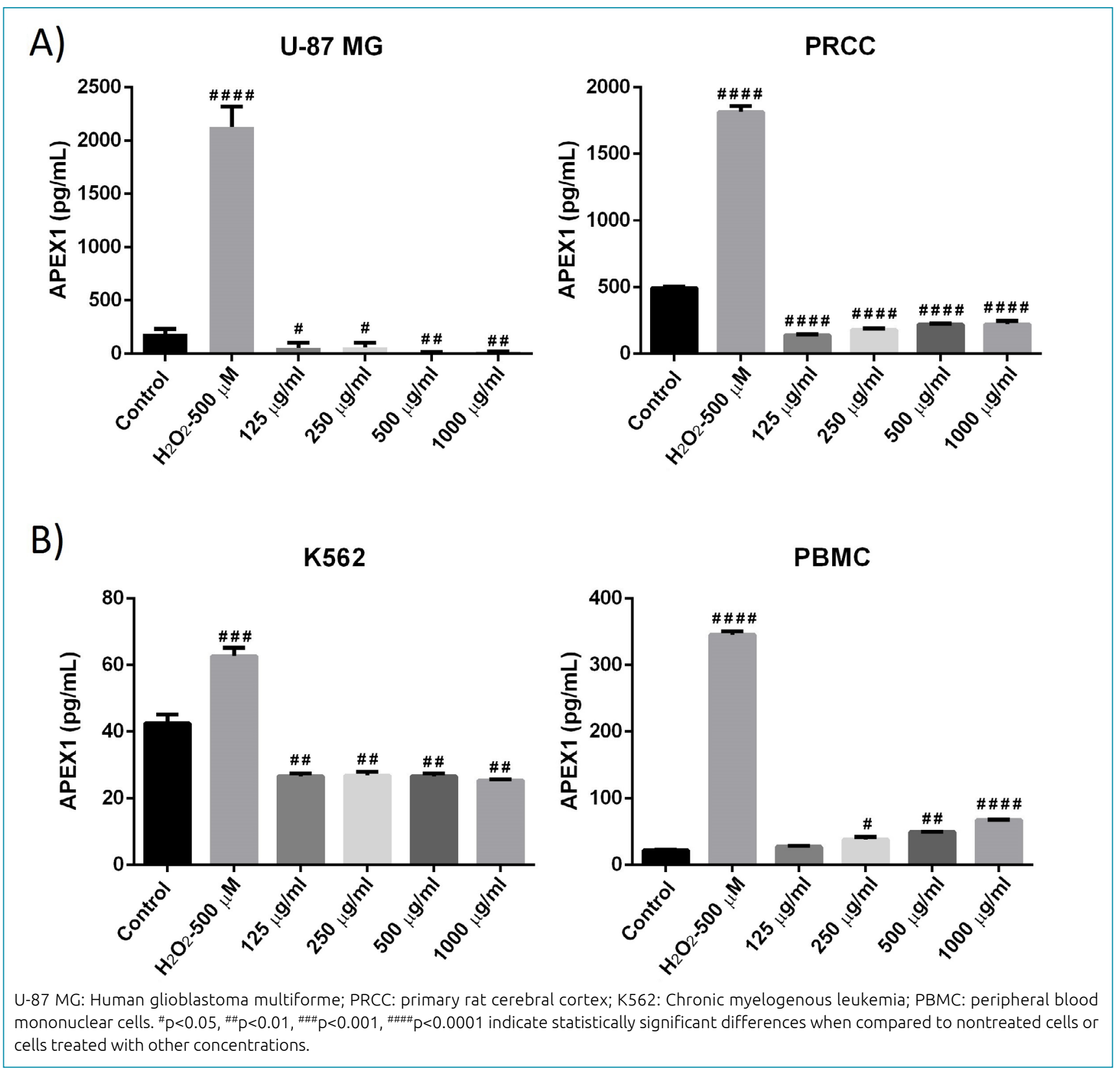

Figure 4. Effects of the I. graveolens extract on apurinic/apyrimidinic endodeoxyribonuclease 1 level in cell lines: (A) Human glioblastoma multiforme and primary rat cerebral cortex and (B) Chronic myelogenous leukemia and peripheral blood mononuclear. Values are expressed as meanıstandard deviation of three independent replicates.

of I. graveolens on the aggressive solid tumor U-87 MG, liquid malignancy K562 cells, and non-cancerous cells.

Our results clearly showed that extracts of $I$. graveolens exhibited cytotoxic effects toward U-87 MG and K562 cells in a dose-dependent manner. The highest $(1000 \mu \mathrm{g} / \mathrm{mL})$ dose of the extract exerted a highly cytotoxic effect by suppressing the viability of U-87 MG cells 50\% without any harmful effects on normal cells. The results of this study are consistent with the previous studies on I. graveolens. The crude oil and some pure volatile compounds of I. graveolens showed antiproliferative activity on the breast cancer cells ${ }^{11}$. In another study, bornyl acetate and essential oil from I. graveolens caused the growth inhibition of HeLa, HT29, A549, MCF7, and FL (human amnion) cells. The essential oil and cisplatin have also exhibited the same inhibitory effect on FL normal cells ${ }^{12}$. I. graveolens significantly increased the LDH release in U-87 MG and K562 cells at higher doses. However, the extracts did not affect LDH release on healthy PRCC and PBMCs, except the increased LDH level in PRCC at $1000 \mu \mathrm{g} / \mathrm{mL}$ dose only. It has 
been reported that the induction of $\mathrm{LDH}$ release in glioma cells had antiproliferative effects. Also, unsaturated fatty acids are high in glia and glioma cell membranes, their peroxidation damages the double-layer structure of the membrane, and this negatively affects important cellular events ${ }^{13}$. Lipid peroxidation-induced cell membrane damages may be associated with the enhanced oxidative stress. TOS is used to determine the oxidative damage and the total response created by antioxidant systems against oxidative stress ${ }^{14}$. I. graveolens extracts did not show any statistically significant effect on TOS levels in U-87 MG, PRCC, and PBMC cell lines, while TOS levels decreased in K562 cells. Reactive oxygen species (ROS) plays an important role in the onset and progression of cancer, and although medium ROS levels cause tumor development, excessive levels of ROS suppress tumor progression ${ }^{15}$. The similarity between TOS levels of control and extract-treated glioblastoma cells may be associated with the suppression of excessive oxidant levels. Thus, high oxidative stress is known to cause brain tumor development by damaging cell components ${ }^{16}$. Furthermore, the controversial role of oxidative stress in the suppression of tumor progression may be associated with non-specific oxidative damage to biomolecules in leukemic cells ${ }^{17}$. The results of this study revealed that I. graveolens at high concentrations led to apoptosis without causing oxidative stress on cancer cells.

Furthermore, a positive correlation was found between oxidative stress values and APE1 activity on K562 and U-87 MG cells. Oxidative stress in gliomas was shown to increase APE1 activity and, as a result, promote resistance to chemotherapy drugs $^{18}$. In this study, I. graveolens significantly reduced the APE1 levels on U-87 MG compared with the control, without increasing oxidative stress. On the other hand, unrepaired abasic sites strongly block DNA replication. Accordingly, the blocking of DNA repair increases cell death in cancer ${ }^{19}$. Thus, the antisense suppression of APE1 as a way of decreasing base excision repair activity enhances the cytotoxicity of chemotherapy in glioma cells ${ }^{20}$. The inverse relationship between cell death and APE1 expression has been established in several studies ${ }^{21}$. It was also demonstrated that glioma cell lines with high APE1 activity also have high radioactive resistance ${ }^{22}$. The decreasing radiation resistance on the cancer cell is more effective in the treatment of glioblastoma that is mandatory to radiotherapy with chemotherapy ${ }^{23}$. Thus, APE1 inhibitors may be a promising new target factor for the treatment strategy of brain cancer ${ }^{24}$. The results of this study revealed that increasing the effectiveness of chemoradiotherapy via inhibition of APE1 provides an advantage for glioblastoma therapy.

\section{CONCLUSIONS}

The results of this study first represented that the aqueous extract of I. graveolens possesses antiproliferative and cytotoxic activity and also dysfunction in DNA repair mechanism without inducing oxidative stress against human glioblastoma cancer and human leukemic cells in vitro. Further comprehensive studies are necessary to identify the active compounds from I. graveolens and also to investigate the action mechanism of these compounds on various cancer types.

\section{AUTHORS' CONTRIBUTIONS}

KK: Conceptualization, Data curation, Formal Analysis, Writing - original draft, Writing - review \& editing. FA: Data curation, Formal Analysis, Investigation, Writing - review \& editing. NSO: Data curation, Formal Analysis, Investigation, Writing review \& editing. FG: Project administration. AT: Data curation. OOA: Data curation. OC: Data curation. GYD: Data curation.

\section{REFERENCES}

1. Coste $\mathrm{H}$, Flahault $\mathrm{CH}$. Flore descriptive et illustrée de la France, de la corse et des contrées limitrophes. Librairie scientifique et technique. Blanchard: Paris. 1985;2.

2. Topçu G, Öksüz S, Shieh HL, Cordell GA, Pezzuto JM, BozokJohansson C. Cytotoxic and antibacterial sesquiterpenes from Inula graveolens. Phytochemistry 1993;33(2):407-10. https:// doi.org/10.1016/0031-9422(93)85529-Z

3. Guinoiseau E, Luciani A, Rossi PG, Quilichini Y, Ternengo S, Bradesi $P$, et al. Cellular effects induced by Inula graveolens and Santolina corsica essential oils on Staphylococcus aureus. Eur J Clin Microbiol Infect Dis. 2010;29(7):873-9. https://doi. org/10.1007/s10096-010-0943-x

4. Al-Fartosy AJM. Antioxidant properties of methanolic extract from Inula graveolens L. Turk J Agric For. 2011;35(6): 591-6. https://doi.org/10.3906/tar-1010-1268
5. Blanc MC, Muselli A, Bradesi P, Casanova J. Chemical composition and variability of the essential oil of Inula graveolens from Corsica. Flavour Frag J. 2004;19(4):314. https://doi.org/10.1002/ffj.1304

6. Silinsin M, Bursal E. UHPLC-MS/MS phenolic profiling and in vitro antioxidant activities of Inula graveolens (L.) Desf. Nat Prod Res. 2018;32(12):1467-71. https://doi.org/10.1080/14 786419.2017 .1350673

7. Sellem I, Chakchouk-Mtibaa A, Zaghden H, Smaoui S, Ennouri K, Mellouli L. Harvesting season dependent variation in chemical composition and biological activities of the essential oil obtained from Inula graveolens (L.) grown in Chebba (Tunisia) salt marsh. Arab Chem. 2020;13(3):4835-45. https://doi.org/10.1016/j. arabjc.2020.01.013 
8. Badrawil DIF. Study the possible effect of Inula Graveolens L. methanolic extract on antioxidant status in track and field male athletes. J Stud Res Sport Educ. 2019;59:158-72.

9. Tiwari S. Plants: a rich source of herbal medicine. J Nat Prod. 2008; 1:27-35.

10. Aggarwal BB, Shishodia S. Molecular targets of dietary agents for prevention and therapy of cancer. Biochem Pharmacol. 2006;71(10):1397-421. https://doi.org/10.1016/J.bcp.2006.02.009

11. Afifi FU, Kasabri V, Abaza IM. GC-MS composition and antiproliferative activity of Inula graveolens (L.) Desf. essential oil. AJMAP. 2015;1(1):57-66.

12. Karan T, Yildiz I, Aydin A, Erenler R. Inhibition of Various Cancer Cells Proliferation of Bornyl Acetate and Essential Oil from Inula graveolens (Linnaeus) Desf. Rec Nat Prod. 2018;12(3):273-83. https://doi.org/10.25135/rnp.30.17.09.057

13. Schmidt F, Knobbe CB, Frank B, Wolburg H, Weller M. The topoisomerase II inhibitor, genistein, induces G2/M arrest and apoptosis in human malignant glioma cell lines. Oncol Rep. 2008;19(4):1061-6. PMID: 18357397

14. Lotito SB, Frei B. Relevance of apple polyphenols as antioxidants in human plasma: contrasting in vitro and in vivo effects. Free Radic Biol Med. 2004;36(2):201-11. https://doi.org/10.1016/j. freeradbiomed.2003.10.005

15. Halliwell B. Can oxidative DNA damage be used as a biomarker of cancer risk in humans? Problems, resolutions and preliminary results from nutritional supplementation studies. Free Radic Res. 1998;29(6):469-86. https://doi. org/10.1080/10715769800300531

16. Hussain SP, Hofseth $\sqcup$, Harris CC. Radical causes of cancer. Nat Rev Cancer. 2003;3(4):276-85. https://doi.org/10.1038/nrc1046

17. Udensi UK, Tchounwou PB. Dual effect of oxidative stress on leukemia cancer induction and treatment. J Exp Clin Cancer Res. 2014;33:106. https://doi.org/10.1186/s13046-014-0106-5
18. Silber JR, Bobola MS, Blank A, Schoeler KD, Haroldson PD, Huynh MB, et al. The apurinic/apyrimidinic endonuclease activity of Ape1/Ref-1 contributes to human glioma cell resistance to alkylating agents and is elevated by oxidative stress. Clin Cancer Res. 2002;8(9):3008-18. PMID: 12231548

19. Madhusudan S, Hickson ID. DNA repair inhibition: a selective tumour targeting strategy. Trends Mol Med. 2005;11(11):50311. https://doi.org/10.1016/j.molmed.2005.09.004

20. Montaldi AP, Godoy PR, Sakamoto-Hojo ET. APE1/REF-1 downregulation enhances the cytotoxic effects of temozolomide in a resistant glioblastoma cell line. Mutat Res Genet Toxicol Environ Mutagen. 2015;793:19-29. https://doi.org/10.1016/j. mrgentox.2015.06.001

21. Robertson KA, Hill DP, Xu Y, Liu L, Van Epps S, Hockenbery DM, et al. Down-regulation of apurinic/apyrimidinic endonuclease expression is associated with the induction of apoptosis in differentiating myeloid leukemia cells. Cell Growth Differ. 1997;8(4):443-9. PMID: 9101090

22. Ono Y, Matsumoto K, Furuta T, Ohmoto T, Akiyama K, Seki S. Relationship between expression of a major apurinic/apyrimidinic endonuclease (APEX nuclease) and susceptibility to genotoxic agents in human glioma cell lines. J Neurooncol. 1995;25(3):183-92. https://doi. org/10.1007/BF01053151

23. Stupp R, Mason WP, van den Bent MJ, Weller M, Fisher B, Taphoorn MJ, et al. Radiotherapy plus concomitant and adjuvant temozolomide for glioblastoma. N Engl J Med. 2005;352(10):987-96. https://doi.org/10.1056/ NEJMoa043330

24. Mohammed MZ, Vyjayanti VN, Laughton CA, Dekker LV, Fischer PM, Wilson DM 3rd, et al. Development and evaluation of human AP endonuclease inhibitors in melanoma and glioma cell lines. Br J Cancer. 2011;104(4):653-63. https:// doi.org/10.1038/sj.bjc.6606058 